

\title{
The Euro Changeover and its Effects on Price Transparency and Inflation.
}

\author{
Wioletta Dziuda and Giovanni Mastrobuoni
}

First version May 2005, this version July $2006^{\dagger}$

*Wioletta Dziuda, Princeton University, wdziuda@princeton.edu; Giovanni Mastrobuoni, Collegio Carlo Alberto, giovanni.mastrobuoni@collegiocarloalberto.it. We thank Orley Ashenfelter, Arnaud Costinot, Franco Peracchi, Hélène Rey, Julio J. Rotemberg, Mike Rothshild, and Matt Weinberg.

†C 2006 by Giovanni Mastrobuoni and Wioletta Dziuda. Any opinions expressed here are those of the authors and not those of the Fondazione Collegio Carlo Alberto. 


\begin{abstract}
Despite the expectations of economists that the euro changeover would have no effect on prices, we show that European consumers perceived the contrary. The data indicate that consumers based their perceptions about inflation on goods that are cheaper and more frequently purchased. We use this insight to develop and estimate a model of imperfect information that explains why these goods were subject to higher price growth after the changeover. The data indicate that some retailers, aware of the consumers' difficulties in adopting the new currency, used the changeover to increase profits by increasing prices. We also propose an explanation of why this effect was smaller in more concentrated retail markets.
\end{abstract}

Keywords: euro, currency changeover, imperfect information, search costs, price setting.

JEL classification codes: D83, F33, L11 


\section{Introduction}

On January 1st, 2002, the euro was introduced as legal tender in twelve European Union (EU) countries. Given that the exchange rates between those countries had been fixed three years earlier, when the euro was launched as an electronic currency many predicted that the cash changeover would have little effect on prices. In fact, the average inflation in the eurozone turned out to be not exceptionally high and the operation was considered a success.

In light of this, it is puzzling that most EU citizens think that the introduction of the euro has triggered a price increase. Around 70 percent believe that prices have been rounded up. Figure 1 shows that in the eurozone perceived inflation significantly exceeds actual inflation only in the posteuro period, while that does not seem to be the case in non-euro EU countries, namely Sweden, Denmark, and the United Kingdom.

Were most Europeans wrong, or did the euro have some effect on prices? The main aim of this paper is to show that the changeover contributed to inflation, explain why this has not been observed in the aggregated data, and describe the mechanism that we believe lies behind people's perceptions that the euro is responsible for price increases.

We propose a model in which consumers are rational, but have difficulty dealing with prices after a cash changeover. A new currency decreases the transparency of prices, hindering price comparisons. That weakens competition between retailers. Small differences in price levels are not perfectly observable which generates incentives to increase prices. As a result, the equilibrium price is higher after the changeover, even in competitive markets. We argue that for reasonable assumptions about the relationship between the changeover and price transparency, less expensive goods should experience larger price increases. Given that the perception of inflation is likely to be based on prices of cheaper, more frequently bought goods, the currency changeover generates a divergence between perceived and actual inflation (see also Del Giovane and Sabbatini, 2004, Guiso, 2003). 
Within the model, we analyze how the effect of the changeover depends upon the market structure. We assume that retailers can improve consumers' price perception by investing in transparency-enhancing measures, such as advertising, dual pricing, explicit cross-shop comparisons, etc. When transparency increases consumers are more likely to notice shops that lower their prices. Lowering the price may result in higher profit if enough consumers notice it. Transparencyenhancing investment is costly and it will be undertaken only by shops that benefit from it the most. In our model these are the shops that operate in a relatively concentrated market. We find that higher market concentration leads to lower euro-related inflation. ${ }^{1}$

We find strong support for our model in the data. First, based on the Eurobarometer survey we analyze self-reported attitudes toward the euro. We find that many EU citizens had problems dealing with the new currency. Among other things, when shopping they thought in terms of the old currency, felt a need for dual pricing, and had problems with remembering and comparing prices.

Second, we analyze the relationship between inflation and price levels. Using Eurostat's HICP data on inflation of individual product categories (items), we provide strong evidence that after the introduction of the euro, cheaper products experienced higher price increases. We use an optimal matching algorithm to predict inflation rates of single product categories and show that the model systematically underpredicts inflation rates of cheaper products after the euro was introduced. We

\footnotetext{
${ }^{1}$ We found anecdotal evidence supporting our model. On their website, Carrefour, the leading retailer in 6 of the 12 euro countries, and the second largest retailer in the world, states "Mission Euro, Mission Accomplished!":

"As a major retailer, Carrefour played a key role in the success of the historic changeover to the euro. The fact is that customers relied on the Group's banners to welcome them just as warmly as on any other day, make their task easier, assist them to find their way around the new system, and answer their queries."

Carrefour was also committed to "... 2. coach everyone in the euro by learning the new value of products together; 3. no price increases during the months of the changeover period (apart from normal seasonal variations); 4. rounding up prices in a way that ensures no price increases for the customer $[$ sic! $]$; ...; 6. putting exceptional measures in place to assist all its customers during the changeover to the euro; 7 . continuing to clearly display prices in both currencies for a minimum of 6 months." Unless we believe that Carrefour was motivated by benevolent intensions, all these strategies were likely to be profit-maximizing.
} 
call this prediction error the euro-related inflation.

We show that countries with higher euro-related inflation are those in which consumers perceived inflation to be high. Using consumers' perceptions as a proxy for actual price changes, we analyze the relationship between price transparency and price changes. We find that countries whose citizens report more problems using the new currency have higher inflation for cheap goods. Finally, consistent with our model, we find a very strong negative correlation between market concentration and inflation.

The layout of the paper is as follows: In Section 2 we present a short overview of the literature. In Section 3 we outline the formal model. Section 4 summarizes the evidence that consumers experienced difficulty dealing with new currency. In Section 5 we test the model. Section 6 concludes. The data are described in the Appendix.

\section{Related literature}

The European Statistical office (EUROSTAT, 2003) found that the euro changeover had a very weak, if at all, effect on aggregate inflation. Angelini and Lippi (2005) analyze the behavior of prices using cash withdrawals from ATM and find no evidence for the euro-related price increase.

Some authors pointed out that consumers' perception of high inflation, despite the low inflation rates reported in official statistics, might come from patterns of inflation of certain products. Ercolani and Dutta (2006) find little evidence of large aggregated price changes, but they show that certain sectors experienced substantial price increases. At least three explanations for increases in sectoral inflation have been proposed, menu costs, asymmetric rounding to attractive prices, and consumers' confusion about prices. Hobijn et al. (2004) and Gaiotti and Lippi (2005) find evidence for a large price increase in the restaurant sector and attribute that to menu cost and sticky prices. They argue that as a result of the currency changeover all restaurants were forced to incur menu costs at the same time, and that they all adjusted prices at the same time, generating a spike 
in inflation. ${ }^{2}$ Additionally, menu costs were incorporated in prices at the time of the changeover, and that contributed further to inflation. While this assumption seems to hold for restaurants, a survey among businesses organized by the National Bank of Belgium shows that 83 percent of the cost related to the changeover was borne and incorporated into prices before the changeover (NBB, 2002). Even for the retail sector, where one might expect less planning, 73 percent of the costs were transferred to consumers before January 2002.

Moreover, these papers do not seem to provide a complete description of the euro effect. In particular, they do not explain the relationship between inflation and the euro-related difficulty consumers reported, and, since menu costs are likely to be similar across countries, they cannot explain the observed heterogeneity across countries in our measure of euro-related inflation.

Another strand of literature has focused on how rounding to attractive prices can trigger inflation at the time of changeover if retailers are unwilling to round down prices (Aucremanne and Cornille, 2001). The distance between pre and post-euro attractive prices depends on the exchange rate, and might therefore differ across countries. While rounding to attractive prices is able to introduce heterogeneity across countries, it is unclear how much it is able to explain the observed heterogeneity in inflation across price levels, and it certainly doesn't explain the relationship between inflation and the consumers' difficulty when dealing with the euro.

Similarly to us, Gaiotti and Lippi (2005) propose a decreased price transparency as an alternative explanation for the euro-related inflation. In their model with some probability consumers do not notice the price change and that generates incentives for the producers to increase prices. Contrary to our paper, in their model consumers are not fully rational, since they fail to predict the equilibrium price increase. Additionally, the authors assume the probability of not noticing a price change is invariant to the magnitude of the price, and this makes their profit maximizing interior solution only a local maximum, as charging a price equal to infinity would bring an infinite

\footnotetext{
${ }^{2}$ Hobijn et al. (2004) use Eurostat's month-to-month inflation (HICP) for restaurants and cafes, while Gaiotti and Lippi (2005) use Italian data taken from a restaurant guide book.
} 
profit.

Adriani et al. (2003) propose a model where consumers are either locals or tourists, and tourists lack any information about the quality of food served by restaurants. In their model, there are many equilibria which depend on tourists' price expectations. They claim, that the currency changeover may affect expectations, and that in turn may generate a price jump to a higher equilibrium. Their model seems to apply only to restaurants, while most Europeans perceived that after the changeover small retailers increased prices as much as restaurants (Table 1).

There have been also some attempts to explain the difference between perceived and actual inflation. In the popular press it has been argued that one possible reason for the gap is that consumers may have simply used approximated exchange rates. In Italy, for example, the exchange rate is 1,936.27 lire for one euro. If consumers use an exchange rate of 2,000, this can bias perceived inflation by about 3 percent. If this explanation were true, euro countries that have a positive rounding error, like Austria, the Netherlands, and Belgium should have experienced a decrease in perceived inflation, which is not the case.

The main feature distinguishing our paper from the rest of the literature is that we do not focus on a particular sector, we provide a model that identifies the goods that should be subject to higher euro-inflation, and we provide an explanation for the difference between perceived an actual inflation rates. Apart from analyzing the currency changeover, our paper contributes to the literature on competition with imperfect information. There are many models of consumer behavior that attempt to capture the implications of costly information for price determination, but it has been difficult to provide convincing empirical tests for them. Diamond (1971), in a very influential paper, shows that even small search costs could result in noncompetitive outcomes. In another theoretical paper, Salop and Stiglitz (1977) assume that consumers have heterogenous 
costs of gathering information.

\section{Model of price competition under limited price}

\section{transparency}

There are $N$ shops selling an identical product at a constant marginal cost $c$. Shops compete in Bertrand fashion.

There is a continuum of consumers of measure one. Each consumer buys one unit of the good, and tries to minimize the price spent on it. If all shops charge the same price, consumers are uniformly distributed among them. Each consumer knows the distribution of the prices on the market, but does not know the exact location ${ }^{3}$, i.e., she does not know which shop charges which price from the distribution, though she can learn the location by searching, which is costless.

Initially, all prices are expressed in the old currency, which we call lire. Clearly, in equilibrium $p=c$, and consumers are indifferent between shops.

The introduction of a new currency, which we call euro, affects the consumer's perception of prices. She knows the distribution of prices in lire and does not know the location of prices. In every shop she visits, she observes the price in euro, but has difficulties converting it to lire in order to determine which price from the distribution she is facing. Additionally, she has a hard time remembering and comparing prices in euro. The problem with price perception is modeled in the following way. If there are two different prices on the market, ${ }^{4}$ say $p$ and $\hat{p}$, the consumer enters the shop, observes the price in euro, and gets a noisy signal about the corresponding value in lire. The signal may be $H$ or $L$. Signal $H$ suggests that a given shop charges the higher of $p$ and $\hat{p}$, and signal $L$ suggests it charges the lower price. After observing the signal, the consumer decides whether to buy the good in the shop or not. If she does not buy the good, she goes to another shop, where she gets a new signal. She continues in this fashion until either she receives

\footnotetext{
${ }^{3}$ Like in Salop and Stiglitz (1977).

${ }^{4}$ For our analysis it is enough to model price perception for situations with only two distinct prices in the market.
} 
signal $L$ or she visits all the shops. Signals are independent across shops and consumers, and consumers uniformly search all shops, that is, consumers who leave shop 1 go to each shop with equal probability.

Let $q(d)$ be the probability of getting signal $L$ in a shop that charges the euro equivalent of price $p$, when some other shop charges $\hat{p}$, where $d$ is a function of the difference between $\hat{p}$ and $p$. If $\hat{p}$ is very different from $p$, then price $\hat{p}$ expressed in euro will be rarely mistaken for price $p$. We assume that $d=\frac{\hat{p}-p}{c^{\gamma}}$, and $\gamma \in[0,1]$. We want to capture the fact that the higher the price difference the more likely it is that the consumer gets the correct signal. It is questionable, whether the precision of the signal should depend on the absolute or on the relative price difference. On one hand it is easier to spot a difference of 2 euro when the price is 10 euro than when it is 100 euro. On the other hand, the higher the absolute price difference the more consumers lose (in terms of money) by not choosing the lower price. If consumers can affect the precision of the signal by exerting some costly effort then they will exert more effort when the price difference is high in absolute terms. Due to the scope of this paper we do not model this mechanism directly and instead we assume that the price precision depends on $d=\frac{\hat{p}-p}{c^{\gamma}}$, where $\gamma=0$ means that only the absolute difference matters while $\gamma=1$ means that only the relative difference matters.

Additionally, we allow firms to invest in transparency-enhancing measures, such as advertising, explicit cross-price comparison, double pricing etc. Let $\alpha_{i}$ be the level of transparency-enhancing investment by shop $i$ and $\alpha=\frac{1}{N} \sum_{i} \alpha_{i}$ be the average level of investment in the market. Therefore $q\left(\alpha, \frac{\alpha_{i}}{\alpha}, \frac{\hat{p}-p}{c^{\gamma}}\right)$ is the probability of receiving signal $L$ in a shop that charges $p$ and invests $\alpha_{i}$, when the average investment is $\alpha$.

We set $q(\alpha, 1,0)=\frac{1}{2}$, which means that identical prices are indistinguishable. $q_{d}\left(\alpha, \frac{\alpha_{i}}{\alpha}, d\right)>0$, that is, increasing the distance between prices leads to a lower probability of mistake. $q_{d}$ measures price transparency; if $q_{d}\left(\alpha, \frac{\alpha_{i}}{\alpha}, 0\right)=\infty$, there is perfect price perception and if $q_{d}\left(\alpha, \frac{\alpha_{i}}{\alpha}, 0\right)=0$ there is no transparency. ${ }^{5}$ Transparency of prices in every shop is higher, the higher the average in-

\footnotetext{
${ }^{5}$ We believe that this a good approximation of a more complicated model in which perception of the price is $\tilde{p}=$
} 
vestment: $q_{d \alpha}\left(\alpha, \frac{\alpha_{i}}{\alpha}, 0\right)>0$. Also $q_{\alpha}(\alpha, 1,0)=0$, because if all shops make an identical investment and charge an identical price they should attract an identical number of consumers. Additionally, other things equal, consumers in shops with higher investment relative to the market are more likely to receive the correct signal, that is, $q_{\left(\alpha_{i} / \alpha\right)}\left(\alpha, \frac{\alpha_{i}}{\alpha}, d\right)>0$. The last assumption means that consumers prefer shops with higher transparency even if $d=0$. For simplicity we assume $q_{\alpha\left(\alpha_{i} / \alpha\right)}(\alpha, 1,0)=0$, that is the relative investment does not affect the impact of the average investment on transparency.

The cost of investment is $C\left(\alpha_{i}\right)$, where $C^{\prime}>0$. We are looking for an equilibrium in which every shop sets the price and the investment level taking the prices of other shops and the average investment level as given. ${ }^{6}$

Let $\hat{p}$ be the price on the market, once the new currency is introduced. For $\hat{p}$ to be an equilibrium, we need that no shop has an incentive to deviate by charging a different price. Consider a representative shop, call it shop 1 . Shop 1 can raise its price, increasing its profit per customer but losing some of its initial customers who get signal $H$. Alternatively, it may decrease its price, decreasing its profit per customer but capturing new consumers. Charging $p \neq \hat{p}$, shop 1 will retain its customers who get signal $L$, will capture all consumers who get $H$ before reaching shop 1 , and $L$ in shop 1, and will get all consumers, who reach shop 1 at the end.

Let $x\left(q\left(\alpha, \frac{\alpha_{i}}{\alpha}, d\right), q\left(\alpha, \frac{\alpha_{j}}{\alpha}, d\right), N\right)$ be the number of consumers captured by a shop with investment $\alpha_{i}$ and price $p$ when other shops invest $\alpha_{j}$, and charge price $\hat{p}$. We can show that

$$
\frac{\partial x(q(\alpha, 1,0), q(\alpha, 1,0), N)}{\partial p}=-4 \frac{1}{N} \frac{1}{c^{\gamma}} q_{d}(\alpha, 1,0)\left(1-\frac{1}{2}^{N-1}\right)
$$

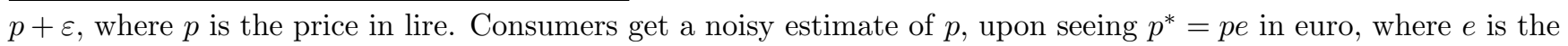
exchange rate. In such a model consumer chooses the shop with the smallest realization of $\tilde{p}$. Also, it suffices to specify the signal structure for two prices on the market, as we will use a Nash equilibrium concept and consider deviation by a single shop.

${ }^{6}$ As we mentioned above, since we assume Bertrand competition in the basic model the price does not depend on market concentration. 


$$
\frac{\partial x(q(\alpha, 1,0), q(\alpha, 1,0), N)}{\partial \alpha_{i}}=4 \frac{1}{N} q_{\left(\alpha_{i} / \alpha\right)}(\alpha, 1,0)\left(1-\frac{1}{2}^{N-1}\right) \frac{1}{\alpha} .
$$

The profit function of each firm is

$$
\Pi\left(\alpha_{i}, p\right)=x\left(q\left(\alpha, \frac{\alpha_{i}}{\alpha}, \hat{p}-p\right), q\left(\alpha, \frac{\alpha_{j}}{\alpha}, \hat{p}-p\right), N\right)(p-c)-C\left(\alpha_{i}\right),
$$

and maximizing it with respect to $p$ and $\alpha_{i}$, we get the first order conditions

$$
\begin{gathered}
\frac{\partial \pi}{\partial p}=\frac{d x}{d p}(p-c)+x=0, \\
\frac{\partial \pi}{\partial \alpha_{i}}=\frac{d x}{d \alpha_{i}}(p-c)-C^{\prime}\left(\alpha_{i}\right)=0 .
\end{gathered}
$$

In a symmetric equilibrium $\alpha=\alpha_{i}$ and $p=\hat{p}$, therefore

$$
\begin{gathered}
\frac{\partial \pi}{\partial p}=\frac{1}{N}\left(-4 \frac{1}{c^{\gamma}} q_{d}(\alpha, 1,0)\left(1-\frac{1}{2}^{N-1}\right)(\hat{p}-c)+1\right)=0 \\
\frac{\partial \pi}{\partial \alpha_{i}}=\frac{1}{N} 4 q_{\left(\alpha_{i} / \alpha\right)}(\alpha, 1,0)\left(1-\frac{1}{2}^{N-1}\right) \frac{1}{\alpha}(\hat{p}-c)-C^{\prime}\left(\alpha_{i}\right)=0 .
\end{gathered}
$$

From equation (1) we get that

$$
\hat{p}-c=\frac{1}{4 \frac{1}{c^{\gamma}} q_{d}(\alpha, 1,0)\left(1-\frac{1}{2}^{N-1}\right)},
$$

We can use this equation to derive the formula for the inflation

$$
\pi=\frac{p_{1}-p_{0}}{p_{0}}=\frac{\hat{p}-c}{c}=\frac{1}{4 c^{1-\gamma} q_{d}(\alpha, 1,0)\left(1-\frac{1}{2}^{N-1}\right)}
$$

Conclusion For any $\gamma<1$ inflation is inversely related to the initial price and to price transparency. 
After the introduction of a new currency, shops try to exploit the imperfect price perception and increase prices, as the increase in price per customer is not entirely offset by the loss of customers. Decreased price transparency increases market power of each shop. Notice that if price perception is perfect, $q_{d}(\alpha, 1,0)=\infty$, we have $p=c$ as before.

We now turn to analyzing the effect of market concentration on prices. Combining (3) together with (2) we get

$$
\frac{q_{\left(\alpha_{i} / \alpha\right)}(\alpha, 1,0)}{\frac{1}{c^{\gamma}} q_{d}(\alpha, 1,0)}-\alpha N C^{\prime}(\alpha)=0 .
$$

Using the implicit function theorem, we get a formula for the derivative of the investment level with respect to the number of shops:

$$
\frac{d \alpha}{d N}=\frac{-q_{d}(\alpha, 1,0) \alpha C^{\prime}(\alpha)}{N\left(q_{d \alpha}(\alpha, 1,0) \alpha C^{\prime}(\alpha)+q_{d}(\alpha, 1,0) C^{\prime}(\alpha)+q_{d}(\alpha, 1,0) \alpha C^{\prime \prime}(\alpha)\right)} .
$$

If the cost function is not too concave, then $\frac{d \alpha}{d N}<0$, that is, the more shops there are, the lower the investment of an individual shop. Investment in transparency increases the number of consumers retained in the shop but does not affect the rate at which new consumers show up. The higher $N$ the less consumers will be affected by increased transparency, therefore investing becomes less profitable.

From equation (3) we get that

$$
\frac{d \pi}{d N}=\frac{-q_{d \alpha}(\alpha, 1,0)\left(1-\frac{1}{2}^{N-1}\right) \frac{d \alpha}{d N}+q_{d}(\alpha, 1,0) \frac{1}{2}^{N-1} \ln \frac{1}{2}}{4 c^{1-\gamma}\left(q_{d}(\alpha, 1,0)\left(1-\frac{1}{2}^{N-1}\right)\right)^{2}}
$$

Inflation is increasing in $N$ if

$$
\frac{\alpha C^{\prime}(\alpha) q_{d \alpha}(\alpha, 1,0)}{q_{d \alpha}(\alpha, 1,0) \alpha C^{\prime}(\alpha)+q_{d}(\alpha, 1,0) C^{\prime}(\alpha)+q_{d}(\alpha, 1,0) \alpha C^{\prime \prime}(\alpha)} \frac{1}{N}\left(2^{N-1}-1\right)>\ln 2
$$

Since $q_{d \alpha}(\alpha, 1,0)>0$, for any set of parameters there exists a $\bar{N}$ such that this condition is 
satisfied.

The intuition for this finding is as follows. The impact of $N$ on prices, $\frac{d \hat{p}}{d N}$, consists of two effects. The first effect is negative and is due to increased competition. Increased competition causes prices to go down. The more shops there are in the market, the more new customers each shop can attract relative to its size by lowering the price. The second effect is positive and is due to lower transparency of prices. The higher $N$ the lower the incentive to invest in transparency and therefore the lower the incentive to undercut the price. However, as the number of shops grows, the first effect becomes smaller and smaller because consumers have to visit a lot of shops before reaching a given shop. Therefore, the negative impact of competition on $p$ becomes small as $N$ increases. That means that for $N$ large enough the effect of a higher investment dominates, and prices grow with $N$.

Define market concentration as the size of an average shop, $\frac{1}{N}$.

Conclusion There is more investment in transparency-enhancing measures in more concentrated market. If market concentration is not too large, the post-changeover price is decreasing in market concentration.

It is important to point out that our results do not depend critically on the assumption that shops compete in Bertrand fashion. In a model of monopolistic competition there would be a higher initial price in more concentrated markets but the incentive to increase prices would still depend on the size of an average shop.

\section{Consumers' attitude toward the euro}

To measure consumers' attitudes toward the euro we use the data from the Eurobarometer survey conducted in 2002. The data are summarized in Table 2.

A significant fraction of Europeans reported having problems when dealing with the euro. 
When asked how difficult it is to remember or to compare prices in euro, around 40 percent said it was either fairly (30 percent) or very (10 percent) difficult. Around 20 percent said they were uncomfortable with the euro. From 7 percent (Ireland) to 28 percent (France) were highly pessimistic, and believed these difficulties to be permanent. Four months after the introduction of the euro, the majority said they always, or often, thought in terms of their old currency and tried to convert the prices. We believe that thinking in terms of old currency and the need to convert suggest lower price transparency $q_{d}$. Converting prices for every good leads to rounding mistakes, making some prices hardly distinguishable. Only around 10 percent of Europeans said that dual pricing had been useless, while a quarter said it was essential. This suggests that prices given in euro were not very transparent. Only from 6 percent (France) to 23 percent (Greece) of the consumers looked solely at the price in euro when both prices were available.

The attitude toward the euro differed across countries. It is interesting that countries that used to have a strong currency and have strong national identities, such as Germany and France, had a higher fraction of people saying they were not pleased with the euro. On the other hand, the two "most European" countries, the ones that also host most of the European institutions, Belgium and Luxembourg, were the least hostile toward the new currency.

The differences in the distribution of age and education were another reason why the attitudes toward the euro varied across countries. Problems with the euro were mainly experienced by older, and less educated people. Among consumers older than 64 the numbers reported in Table 2 are approximately twice as large. Notice that Ireland, which has, by far, the youngest population in Europe, had the lowest fraction of people admitting to having difficulties comparing and remembering prices in euro. A high fraction of consumers also had a hard time dealing with the newly introduced coins, and again, the numbers are twice as large if we restrict the sample to older consumers. ${ }^{7}$ Understating the value of newly introduced euro coins represent another reason small

\footnotetext{
${ }^{7}$ Many European countries did not have coins of reasonable value before the changeover.
} 
absolute and not relative price changes might fall unnoticed.

\section{$5 \quad$ Empirical specification and results}

The main prediction of our model is that the euro-related inflation was higher for lower-priced goods. We know that price changes depend on several factors, and it would be extremely difficult to control for all of them. Instead, we use a treatment and matched control estimation procedure. Define the introduction of the euro as the treatment. The variables of interest are Eurostat's HICP item-specific $(i)$ annual $(t)$ inflation rates $\left(p_{t, i} / p_{t-12, i}-1\right.$, see Appendix $\mathrm{A}$ for a description of the data) in the treated countries $(T)$,

$$
\pi_{i, t}^{T}=f\left(E U R O_{i, t}, p_{i, t}\right)^{T}+g\left(D_{i, t}, S_{i, t}\right)^{T}+\epsilon_{i, t}^{T}
$$

which depend on demand and supply $g(D, S)$ and, according to the model, on the introduction of the euro, $f(.){ }^{8}$ We control for $g(D, S)^{T}$ using information from those countries that didn't introduce the euro, the comparison group $(C)$ :

$$
\pi_{i, t}^{C}=g\left(D_{i, t}, S_{i, t}\right)^{C}+\epsilon_{i, t}^{C}
$$

Instead of just performing a simple difference between treatment and control countries, we use 5 years of pre-treatment (pre-euro) data to construct optimal comparison groups. This is done by estimating for each $\{\mathrm{T}, \mathrm{i}\}$ the following OLS regression:

$$
\pi_{i, t}^{T}=a_{i}+b_{i}^{S W} \pi_{i, t}^{S W}+b_{i}^{U K} \pi_{i, t}^{U K}+b_{i}^{D K} \pi_{i, t}^{D K}+e_{i, t}
$$

where SW, UK, DK denote Sweden, the United Kingdom, and Denmark respectively.

\footnotetext{
${ }^{8}$ In order to better control for seasonality we prefer the use of annual inflation rates over monthly inflation rates, even if that introduces serial correlation in HICP's monthly data.
} 
The purpose is to have the best possible, in terms of mean squared error, estimate of $g\left(D_{i, t}, S_{i, t}\right)^{T}$. Notice that we use only pre-treatment data to avoid confounding $g($.$) with f($.$) . The estimated$ $g($.$) is then equal to$

$$
g\left(D_{i, t}, S_{i, t}\right)^{C}=\widehat{g}\left(D_{i, t}, S_{i, t}\right)^{T}=\widehat{\pi}_{i, t}^{T}
$$

Tables 3 and 4 show the distribution of the R-squared from regression (7) by country and by item. The median R-squared is around 50 percent. There is not much variation across countries. The 10th percentile is around 15 percent and the median is around 45 percent. For no country the fit is uniformly worse or uniformly better. The average number of observation per regression is very close to 60 , because for most items data on all 60 pre-euro MONTHS ( 5 years) are available.

The correlation between the item's average price level and the median R-squared is only -3.7 percent (last row in Table 4), which means that the ability to generate a good comparison group does not correlate with the average price level. Not surprisingly, items whose price depends on world markets, like, for example, Coffee, tea and cocoa and Fuels and lubricants for transport, tend to have very high R-squares, while more locally based items, like Accommodation services and Hairdressing saloons, have low R-squared.

The next step is to estimate the following model

$$
\pi_{i, t}^{T}-\widehat{\pi}_{i, t}^{T}=f\left(E U R O_{i, t}, p_{i, t}\right)^{T}+\tilde{\epsilon}_{i, t}^{T}
$$

where $\tilde{\epsilon}_{i, t}^{T}=\epsilon_{i, t}^{T}+g\left(D_{i, t}, S_{i, t}\right)^{T}-\widehat{g}\left(D_{i, t}, S_{i, t}\right)^{T}$.

We use a non-parametric estimate of $f\left(E U R O_{i, t}, p_{i, t}\right)^{T}$ dividing price levels, information obtained from the Economist Intelligence Unit data (see Appendix $\overline{\mathrm{A}}$ ), into $K$ percentiles. ${ }^{9}$ In order

\footnotetext{
${ }^{9}$ For each euro country $p_{i, t}$ is measured by the average price level in the country and the price level in the 3 non-euro countries. This should reduce measurement error, even though the pooled correlation between price levels in the euro-countries and in the non-euro countries is larger then 99 percent.
} 
to measure price changes at different percentiles, we specify

$$
\begin{gathered}
f\left(E U R O_{i, t}, p_{i, t}\right)^{T}=\sum_{k=1}^{K+1} \beta_{0, k} 1\left(\xi_{k-1} \leq p_{i t}<\xi_{k}\right) \\
+\sum_{k=1}^{K+1} \beta_{1, k} 1\left(\xi_{k-1} \leq p_{i t}<\xi_{k}\right) \times 1(t \geq \mathrm{JAN} 2002)
\end{gathered}
$$

where 1(.) is an indicator function, and $\xi_{k}$ represents the cutoff points for the different percentiles. In this specification $\beta_{1, k}$ measures the difference at the $\mathrm{k}$-th percentile between the post-euro and the pre-euro unpredicted price change.

Figure 2 provides a glimpse of what we find. It shows for each decile the difference between the actual and the predicted inflation rate, $\pi_{i, t}^{T}-\widehat{\pi}_{i, t}^{T}$ during the pre-euro (dotted line), and the post-euro period (dashed line). The shaded area represents the 5 percent confidence interval for the post-euro period. The predicted and the actual price changes are in both periods remarkably close, with the notable exception of the first two deciles after the introduction of the euro. The prediction error at the first two deciles is between $1 / 2$ and $3 / 4$ of a percentage point. Given that average inflation was quite low during 2002, the unpredicted price change in the two deciles explains 25-40 percent of the total price change. The effect on total inflation is going to be roughly equal to $1 / 5$ th of that, quite close to Eurostat's estimate of 0-0.2 percentage points EUROSTAT (2003).

Figure 3 shows how the prediction error differs across countries. Due to the smaller sample size we use price quintiles instead of price deciles. In Spain, Greece, Italy, France, the Netherlands, Belgium, and Luxembourg the model systematically underpredicts inflation at lower quintiles. In the remaining countries the pattern is more complicated. In Portugal the model underestimates inflation rates at the last decile, while in Austria, Luxembourg (beside at the first quintile), Ireland (at the second quintile), and Germany (at the last two quintiles) inflation has been lower than predicted. 
Table 5 displays the estimated $\beta_{1, k} \mathrm{~s}$ from Equation 9. In terms of Figure 3, we are measuring the distance between the dashed line and the dotted line. The equation is estimated using OLS. Since we are using yearly inflation and monthly data, the error terms are going to be correlated over time up to one year. We estimate the standard errors using the Newey-West "sandwich" procedure, allowing for item-specific autocorrelation in the error term of up to 12 months.

At the first quintile all estimates are positive, ranging from almost 0 in Portugal, to 1.88 percentage points in Greece. At this quintile Greece, Spain, Italy, and Luxembourg have the highest unpredicted change in price. In all these four countries, in France and in the Netherlands the effects are significant at a 5 percent level. At the second quintile all those countries except Luxembourg have positive coefficients, though mostly not significant. At the 3rd and 4th quintile the effects are mostly zero, or negative and tend to be not significant. Unpredicted price changes seem to have occurred among goods that are cheaper, which is consistent with our model. The only finding not consistent with our model is the positive estimate for France, Spain and Portugal at the 5th quintile, which is mainly driven by higher than predicted price changes for cars, repairs of cars, hotels, and electricity.

In this specification the effects of the changeover are averaged over the whole post-euro year. There are some reasons to prefer this one-year "pooled" estimate over more flexible specifications. Some shops might have reacted faster than others, and there is no reason to assume that all shops adjusted prices exactly at the time of the changeover. Also, averaging the effect over the whole year 2002 is statistically more conservative. We also analyzed how the euro-related price change varies within the year, but we did not find any clear pattern. ${ }^{10}$

We now move to analyzing the relationship between price transparency and inflation. In Table 1 we see that the fraction of people who believe prices were rounded up after the introduction of the euro are generally high, but vary across countries. Austria, Finland, and Portugal, for example, have fractions equal or below 80 percent, while more than 90 percent of consumers in the

\footnotetext{
${ }^{10}$ Results available upon request.
} 
Netherlands, Greece, Germany, and Spain believe prices were rounded up after the changeover. Figure 4 suggests that this perception is solely based on unexpected price increase at the first two price quintiles. At those two quintiles there is a very strong positive correlation between eurorelated perceived and euro-related actual price changes (63 and 59 percent). The reason here is probably that cheaper products are purchased more frequently, and have a disproportionate weight in people's perceptions about total inflation at the time of the changeover.

Our model predicts that the price increase should be higher the lower the price transparency. Treating perceptions as a proxy for the actual inflation of lower priced goods we can use Eurobarometer's microdata to test this prediction by estimating how those perceptions depend on the difficulties consumers had when dealing with the new currency.

We estimate an ordered probit of perceived euro-related price increases on proxies of price transparency, $q_{d}$. Since some of the differences in perceived inflation are likely to be related to the exchange rate with the euro, to other country specific policies, and to news coverage, country fixed-effects are included in the regressions and standard errors are clustered by country. We control for age and education as they are likely to affect price transparency. People tend to cluster by age and education, both in terms of where they live and purchase goods and in terms of what they consume.

The consumers' ability to get accustomed with new currency seems to have a large and significant impact on the perception of rounding up of prices due to inflation. Table 6 shows that consumers who report the need to convert price to their old currency, have difficulties when comparing or remembering prices, have difficulties with the coins, and feel uncomfortable dealing with prices in euro, perceive higher euro-related inflation. When dual pricing is available, sticking to the old currency increases the perception of inflation. When we control for all these proxies of $q_{d}$ the single most significant proxy is feeling uncomfortable with the euro. Consistent with the idea that older and less educated consumers may be more subject to euro-related inflation we find that these consumers are more likely to perceive that prices went up. 
Finally, the evidence on the relationship between retailers' concentration and euro-related price changes sheds some light on the observed heterogeneity in euro-related inflation. As none of the euro countries is characterized by an exceptionally high market concentration, our theoretical model predicts euro-inflation to be negatively related to market concentration. Figure 5 plots our estimated $\widehat{\beta}_{1, k} \mathrm{~s}$ against retailer concentration. ${ }^{11}$ There is a very strong negative relationship between market concentration and euro-inflation at the first quintile. The relationship is weaker at the second decile and close to zero at all other quintiles.

\section{Conclusions}

Some institutions, including EUROSTAT (2003), have found that the euro changeover had only a very limited effect on overall inflation. However, inflation is an extremely synthetic measure of price growth and does not capture differentiated effects of the changeover on prices. To our knowledge, excluding anecdotal evidence and descriptive studies, these possible differentiated effects have not been fully investigated.

We propose a model in which consumers are fully rational, but after a cash changeover remember and compare prices with some noise. The model predicts higher inflation for lower-priced goods. It also predicts that the effect is lower in less concentrated markets, where some retailers gain from competing in price transparency. We use an optimal matching estimator to analyze the relationship between price levels and inflation in all $12 \mathrm{EU}$ countries that introduced the new currency and in three EU countries that did not, namely Sweden, Denmark, and the United Kingdom. For each treatment group (each euro country) and each product category (Eurostat's HICP items) the matching estimator selects the optimal comparison group based on 60 months of preeuro annual inflation rates. We then compare the post-euro and pre-euro differences in inflation rates between the treatment groups and the comparison groups. In other words, we use Sweden,

\footnotetext{
${ }^{11}$ Since most of the lower priced items contain food products we use retailer concentration in the food industry (see the Appendix A).
} 
Denmark, and the United Kingdom to predict item-specific inflation rates in the eurozone, and then we analyze the prediction errors. We plot these errors against price deciles using information taken from the Economist Intelligence Unit and find evidence that the predictions based on the matching model track the actual inflation rates quite closely, with one notable exception. Following the introduction the euro the model underpredicts inflation rates at the first 2 price deciles.

We show that countries in which consumers perceived inflation to be high are indeed those in which prices at the first quintile rose the fastest. That supports the hypothesis that consumer perception of inflation was based on a different basket of goods than the one used by the official statistics, which generated a gap between the two series. Using perceived inflation as a proxy for the actual one shows that the euro-related inflation is closely related to the consumers' difficulties in dealing with the euro. This relationship has been predicted by our model while it would not arise if menu cost or rounding up to attractive prices were the sole explanations of the price increase.

Our model predicts a negative relationship between market concentration and the euro-related inflation. Using a measure of retailers' market concentration we find evidence supporting this finding.

The analysis sheds some light on what happened after January 2002. Hopefully, it also will help some countries (especially future euro members) with designing better currency changeovers and with predicting their effects. Three countries that have been used as a comparison group, the United Kingdom, Denmark, and Sweden, have a retailer concentration of, respectively, 0.57, 0.76, and 0.95 . Using our results, the predicted inflation rate due to the changeover, would be larger in the United Kingdom than in the other two countries. Enhancing price transparency, educating consumers, and the use of some sort of "price watch," especially among smaller shops, are some of the measures that countries facing a currency change may want to adopt. 


\section{References}

Fabrizio Adriani, Giancarlo Marini, and Pasquale Scaramozzino. The Inflationary Consequences of a Currency Changeover: Evidence from the Michelin Red Guide. CEIS 27, University of Tor Vergata, July 2003.

Paolo Angelini and Francesco Lippi. Did inflation really soar after the euro cash changeover? indirect evidence from atm withdrawals. CEPR Discussion Papers 4950, C.E.P.R. Discussion Papers, March 2005.

Luc Aucremanne and David Cornille. Attractive prices and euro-rounding effects on inflation. Technical report, 2001.

Paolo Del Giovane and Roberto Sabbatini. L'introduzione dell'euro e la divergenza tra inflazione rilevata e percepita. Temi di discussione del Servizio Studi 532, Banca D'Italia, December 2004.

Peter A. Diamond. A model of price adjustment. Journal of Economic Theory, 3(2):156-168, 1971.

EIU. How are prices gathered. Technical report, Economist Intelligence Unit. Online at http://eiu.enumerate.com/.

Marco G. Ercolani and Jayasri Dutta. The euro-changeoverand euro-inflation: Evidence from eurostat's hicp. Discussion Papers 06-03, Department of Economics, University of Birmingham, February 2006.

European Commission. Price Differences for Supermarket Goods in Europe. Technical report, 2000. Internal working document of the Internal Market Directorate General. Online at http://europa.eu.int/.

EUROSTAT. Euro-zone annual inflation down to 1.9\%. Euro-Indicators, Rapid STAT/03 69, May 2003. 
EUROSTAT. Compendium of HICP reference documents (2/2001/B/5). Technical report, Luxembourg, December 2001. Online at http://forum.europa.eu.int/.

Eugenio Gaiotti and Francesco Lippi. Pricing behavior and the introduction of the euro: evidence from a panel of restaurants. Giornale degli Economisti, January 2005. Forthcoming.

Luigi Guiso. Inflazione percepita e rilevata. LaVoce, February 2003. Online at www.lavoce.info.

Bart Hobijn, Federico Ravenna, and Andrea Tambalotti. Menu costs at work: restaurant prices and the introduction of the euro. Staff Reports 195, Federal Reserve Bank of New York, November 2004.

NBB. January 2002 Survey on the Introduction of the Euro. Press Release 6 March 2002, National Bank of Belgium, Brussels, 2002.

Steven Salop and Joseph E. Stiglitz. Bargains and Ripoffs: A Model of Monopolistically Competitive Price Dispersion. Review of Economic Studies, 44(3):493-510, 1977. 


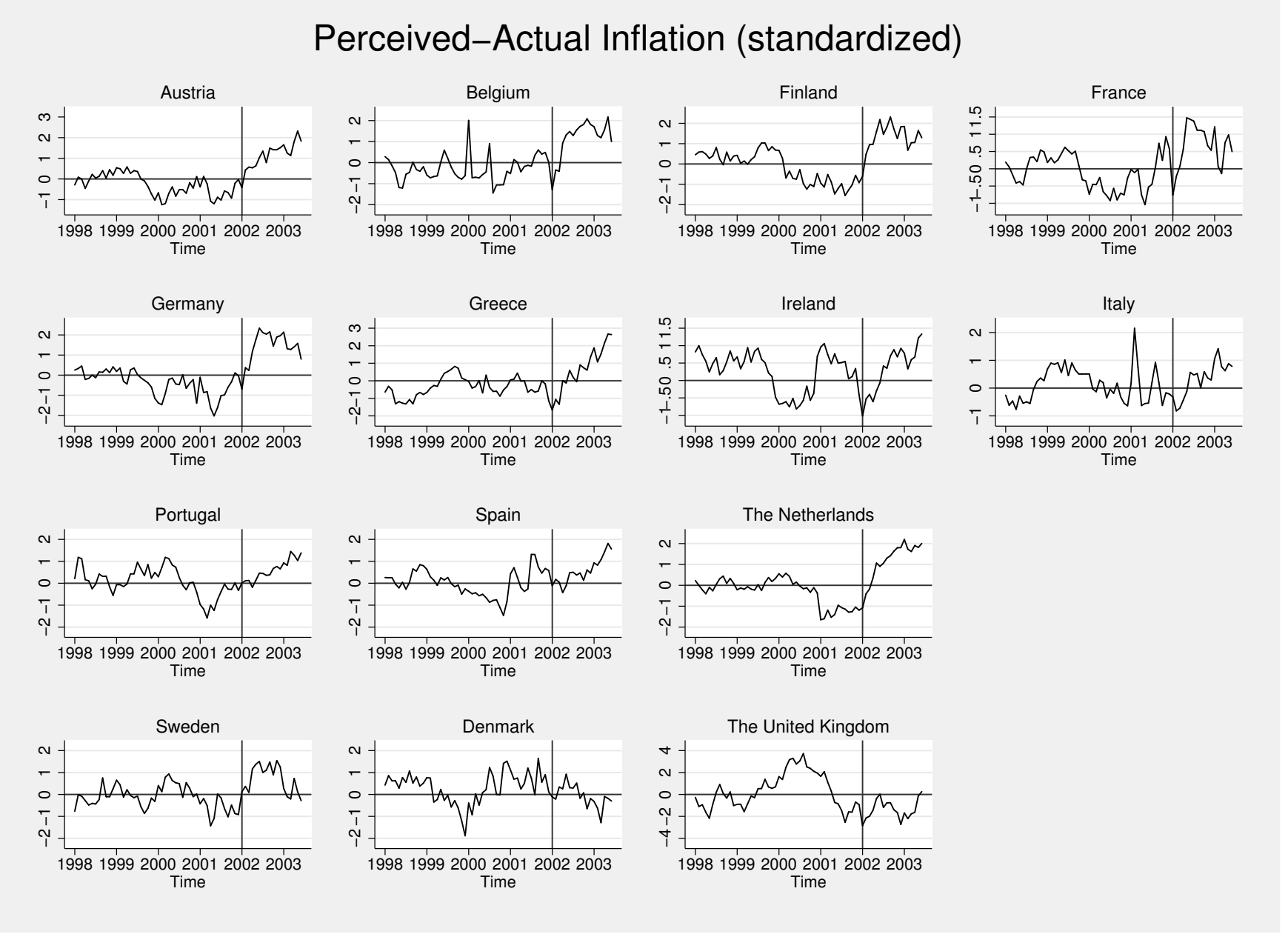

Figure 1: Difference between standardized perceived and standardized actual inflation (in percent). Perceived inflation is based on differences between positive and negative opinions about the level of inflation. Source: Authors' calculations based on the EU Business and Consumer Surveys and on Eurostat data. 


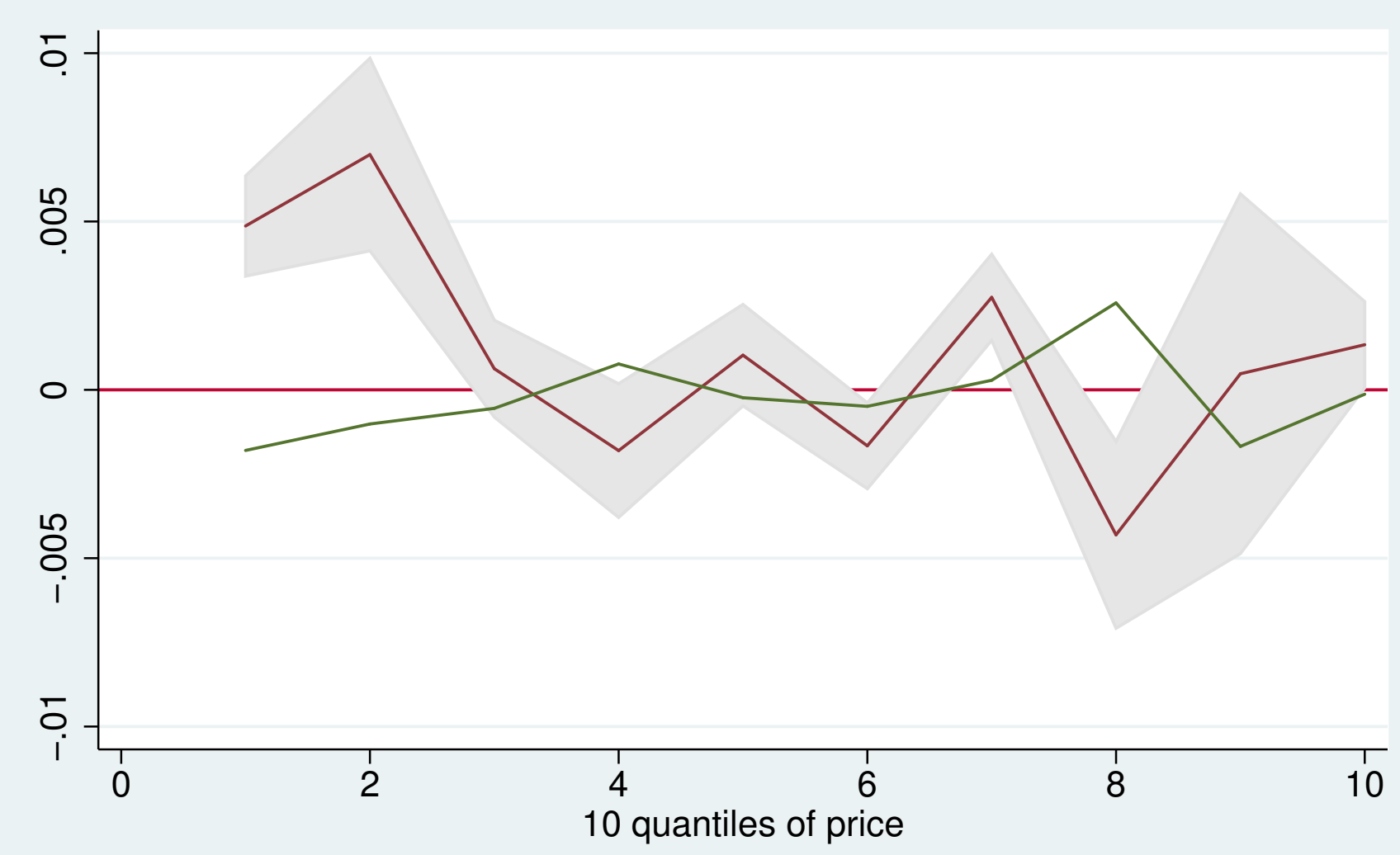

POST/ 95\% Cl

POST: Actual-predicted infl.

PRE: Actual-predicted infl.

Figure 2: Difference between the actual and the predicted annual item specific inflation rate (demeaned and deseasonalized). The predicted inflation rate is based on optimally weighted data for the United Kingdom, Denmark and Sweden. (1) indicates the 1-year post-euro period and (0) the 5-year pre-euro period. Source: Author's calculations using Economist Intelligence Unit and Eurostat data (Appendix A) 

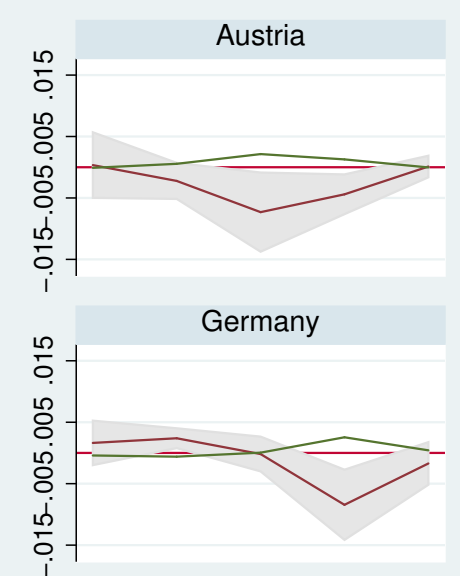

Luxembourg

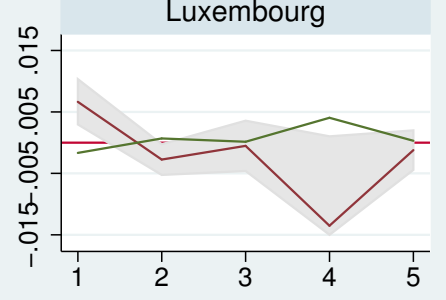

$\mathrm{POST} / 95 \% \mathrm{Cl}$

PRE: Actual-predicted infl.
Finland

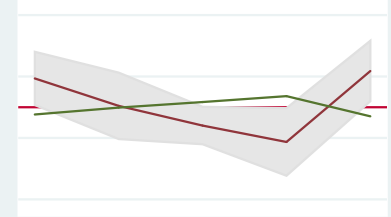

Greece

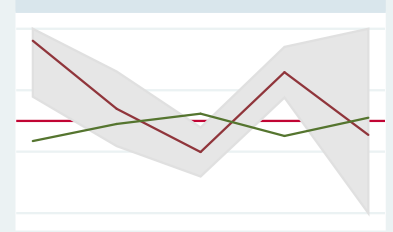

Netherlands

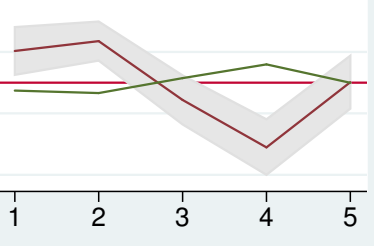

5 quintiles of price

Ireland

Portugal
France
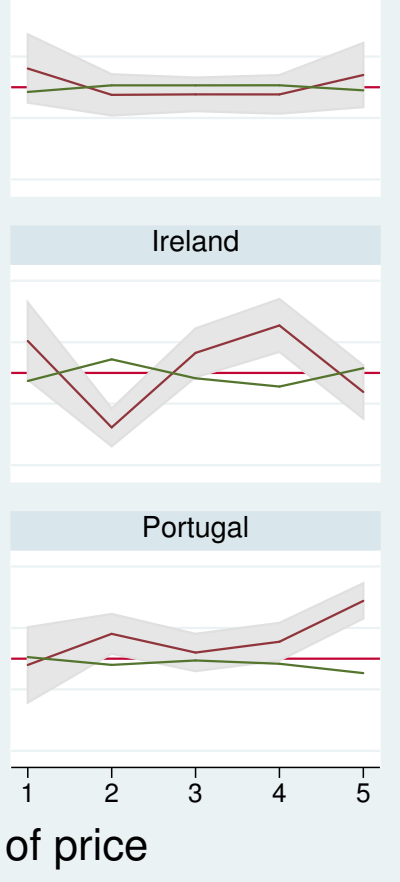

POST: Actual-predicted infl.

Graphs by country

Figure 3: Difference between the actual and the predicted annual item specific inflation rate (demeaned and deseasonalized). (1) indicates the 1-year post-euro period and (0) the 5-year preeuro period. Source: Author's calculations using Economist Intelligence Unit and Eurostat data (Appendix A) 


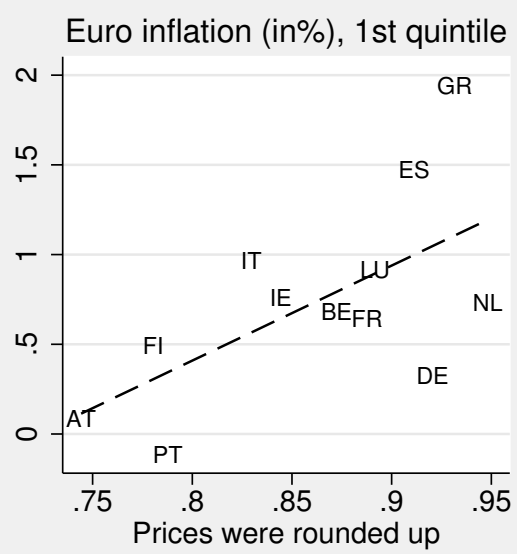

Euro inflation (in\%), 2nd quintile



Euro inflation (in\%), 5th quintile



Euro inflation (in\%), 3rd quintile

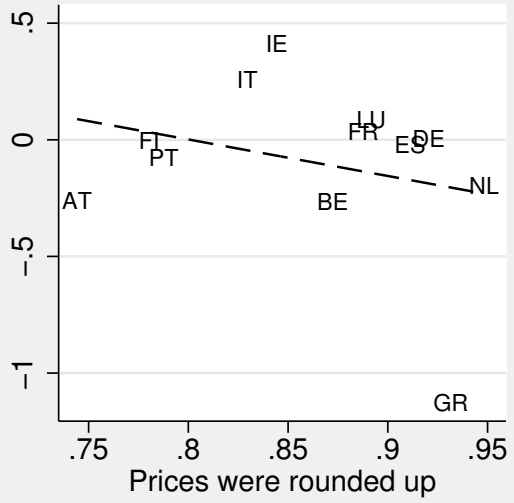

Euro inflation (in\%), 4th quintile

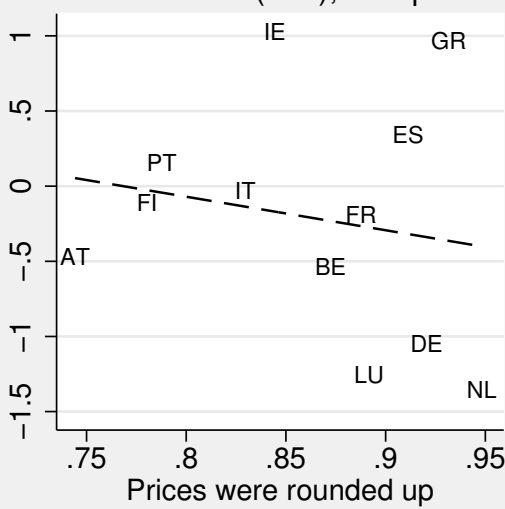

Figure 4: Relationship between perceived inflation and the unpredicted price change. 


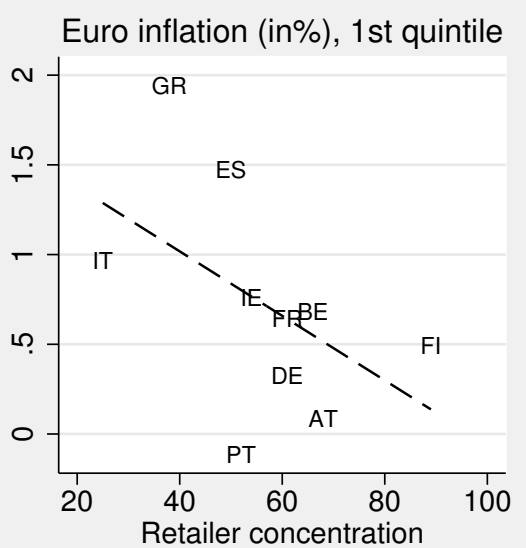

Euro inflation (in\%), 2nd quintile

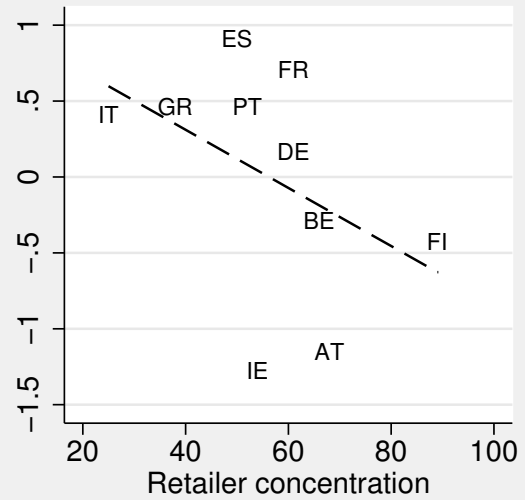

Euro inflation (in\%), 4th quintile
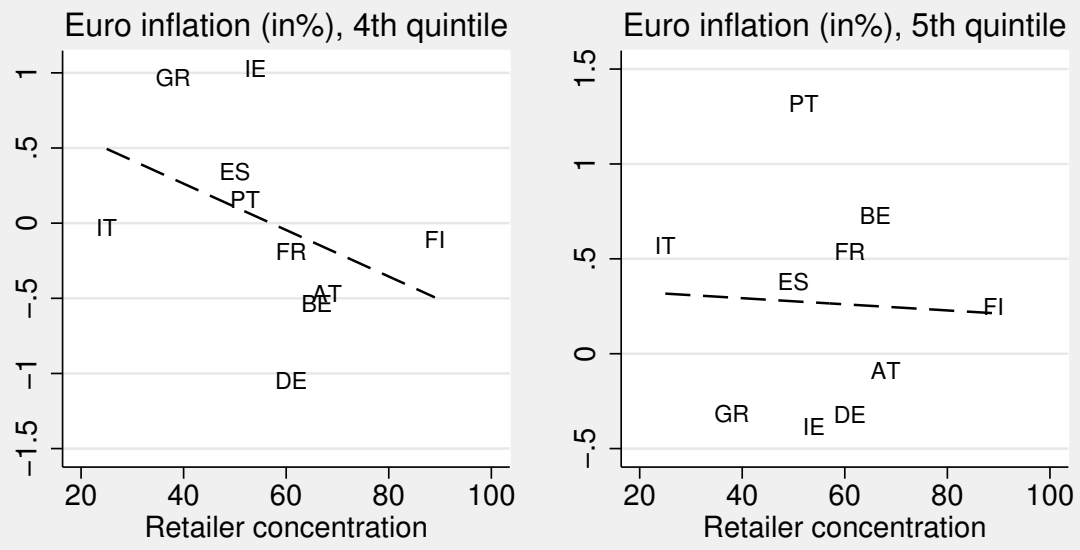

Euro inflation (in\%), 3rd quintile

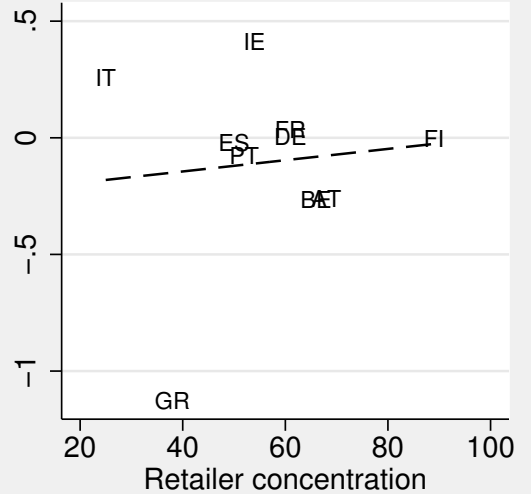

Figure 5: Relationship between perceived inflation and retailer concentration. 


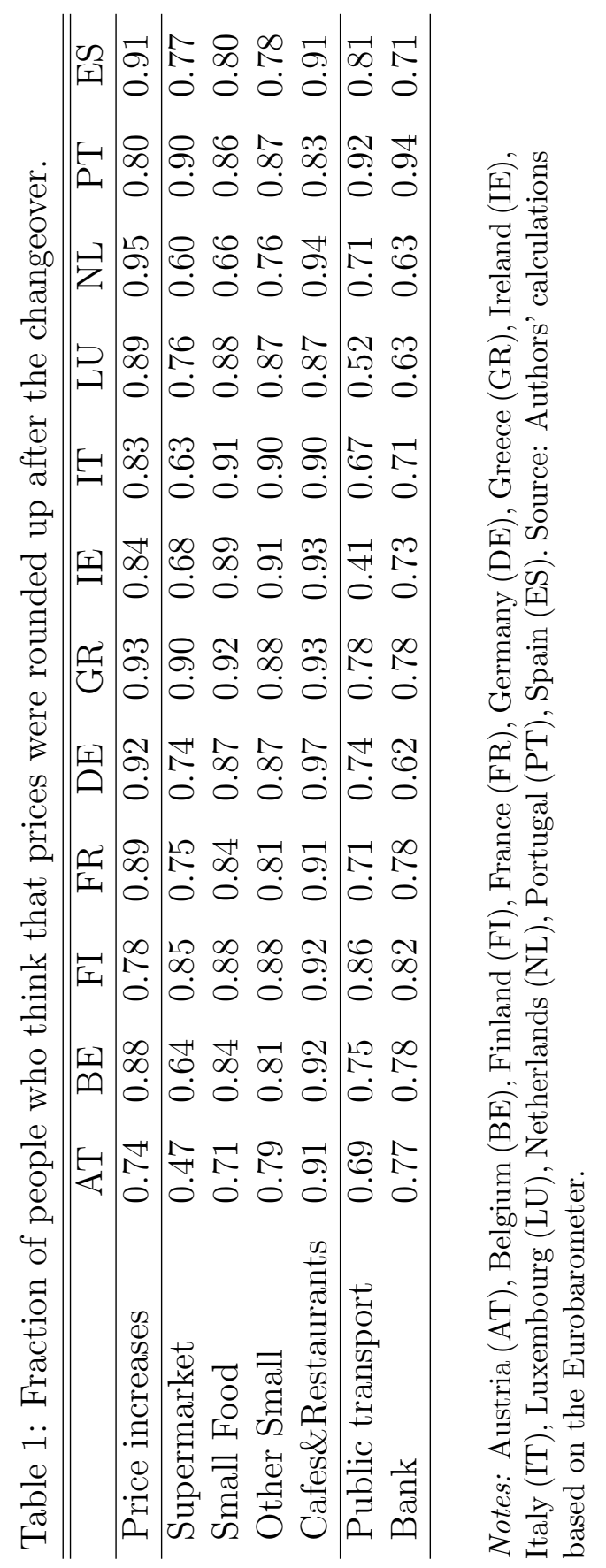




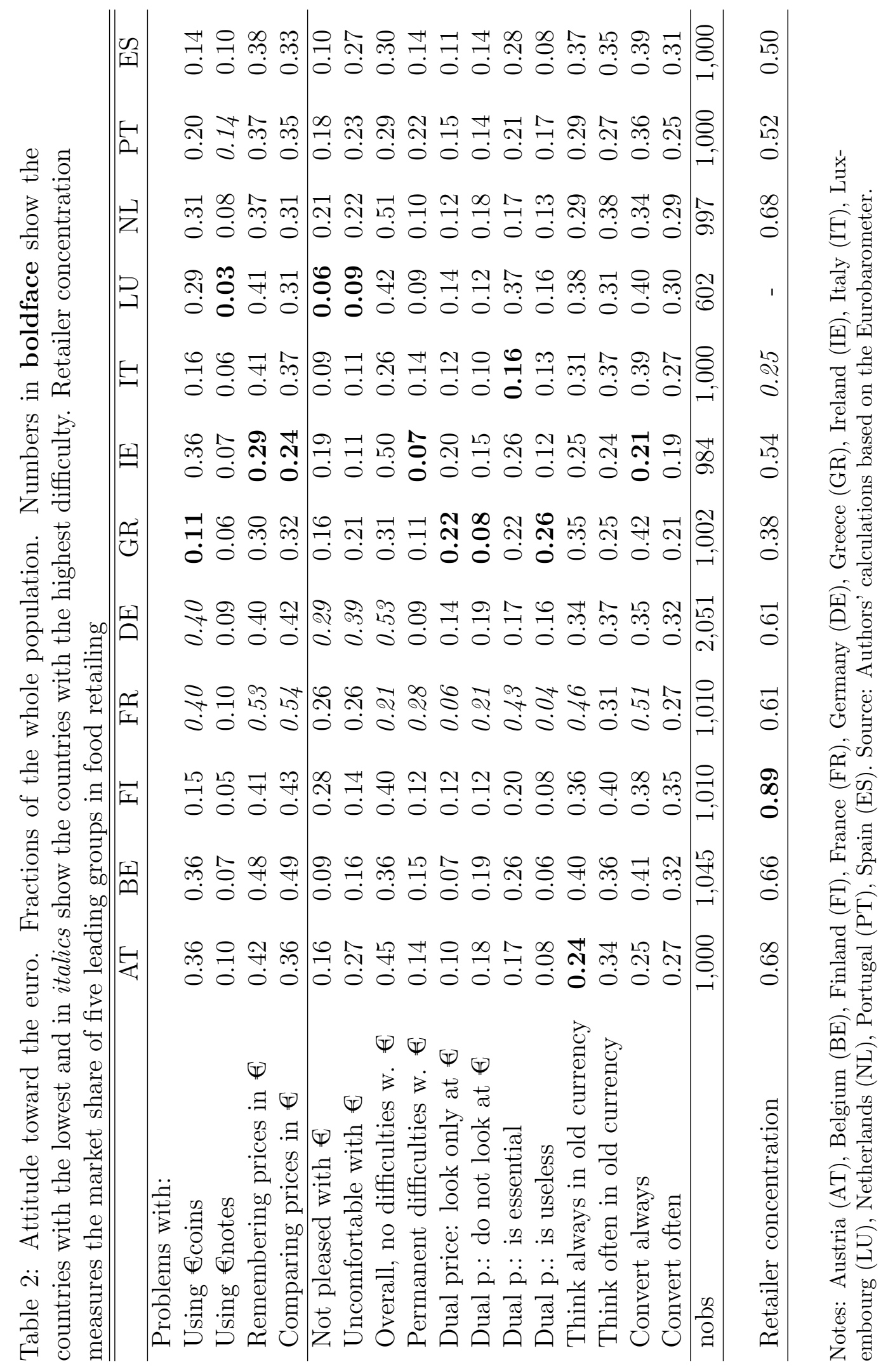


Table 3: Distribution of R-squared from the estimation's first step.

\begin{tabular}{lcccccc}
\hline \hline \multicolumn{7}{c}{ Percentiles of R-squared } \\
& 10 & 25 & 50 & 75 & 90 & $\begin{array}{c}\text { Average num- } \\
\text { ber of obser- } \\
\text { vations }\end{array}$ \\
\hline Austria & $9 \%$ & $17 \%$ & $39 \%$ & $57 \%$ & $75 \%$ & 55.7 \\
Belgium & 10 & 19 & 48 & 70 & 86 & 56.5 \\
Germany & 12 & 31 & 50 & 65 & 81 & 57.3 \\
Spain & 16 & 23 & 50 & 73 & 85 & 56.6 \\
Finland & 14 & 26 & 43 & 64 & 86 & 57.1 \\
France & 13 & 27 & 59 & 68 & 85 & 57.3 \\
Greece & 16 & 28 & 40 & 53 & 75 & 55.3 \\
Ireland & 14 & 28 & 47 & 57 & 76 & 58.3 \\
Italy & 8 & 25 & 46 & 61 & 89 & 56.7 \\
Luxembourg & 12 & 17 & 32 & 63 & 78 & 56.7 \\
The Netherlands & 15 & 25 & 52 & 73 & 85 & 58.3 \\
Portugal & 15 & 28 & 49 & 65 & 74 & 56.7 \\
\hline
\end{tabular}

Notes: R-squared from item (45 in total) and country-specific regression of annual inflation in the euro countries on annual inflation in Sweden, the United Kingdom, and Denmark. 5 years of pre-euro data are used, and the average number of observation is below 60 months because a few missing values. 
Table 4: Matched HICP-items and EIU identification code. Mean and standard deviation of prices in euro, distribution of R-squared from the estimation's first step, and the average pre and post-euro prediction errors.

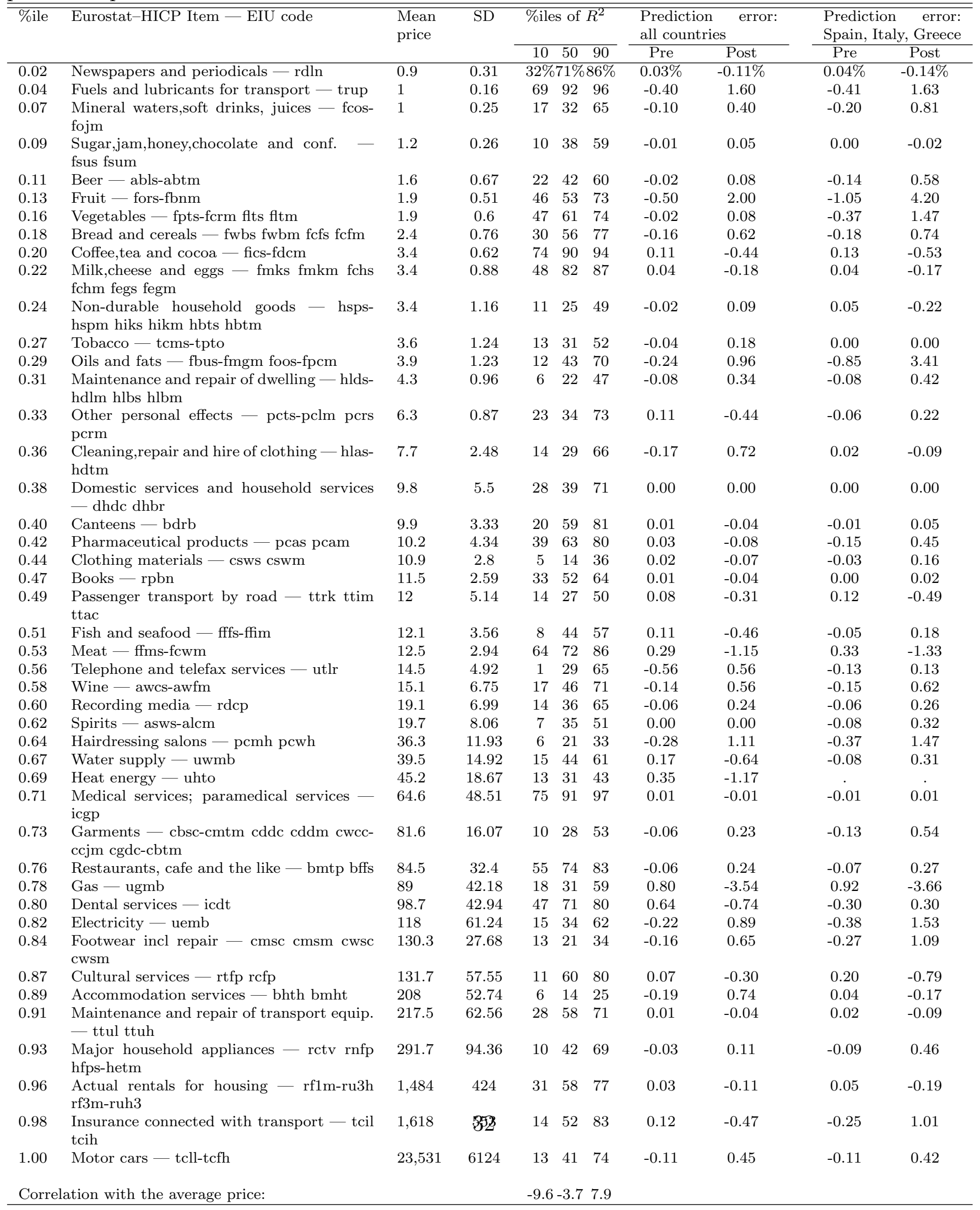


Table 5: Estimates of euro-related annual price growth $\left(100 \times\left[p_{t} / p_{t-12}-1\right]\right)$ on $1 / p$.

\begin{tabular}{|c|c|c|c|c|c|c|}
\hline & 1st quintile & 2nd quintile & 3rd quintile & 4th quintile & 5th quintile & \# obs. \\
\hline \multirow[t]{2}{*}{ Austria } & 0.08 & -1.15 & -0.26 & -0.47 & -0.09 & 2508 \\
\hline & $(0.41)$ & $(0.83)$ & $(0.30)$ & $(0.55)$ & $(0.24)$ & \\
\hline \multirow[t]{2}{*}{ Belgium } & 0.68 & -0.29 & -0.27 & -0.54 & 0.73 & 2486 \\
\hline & $(0.45)$ & $(0.26)$ & $(0.37)$ & $(0.86)$ & $(0.39)$ & \\
\hline \multirow[t]{2}{*}{ Germany } & 0.32 & 0.17 & 0.00 & -1.05 & -0.32 & 2580 \\
\hline & $(0.35)$ & $(0.25)$ & $(0.31)$ & $(0.99)$ & $(0.55)$ & \\
\hline \multirow[t]{2}{*}{ Spain } & 1.47 & 0.91 & -0.02 & 0.34 & 0.38 & 2376 \\
\hline & $(0.29)$ & $(0.59)$ & $(0.24)$ & $(0.75)$ & $(0.27)$ & \\
\hline \multirow[t]{2}{*}{ Finland } & 0.49 & -0.43 & 0.00 & -0.11 & 0.25 & 2568 \\
\hline & $(0.60)$ & $(0.26)$ & $(0.26)$ & $(0.41)$ & $(0.30)$ & 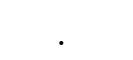 \\
\hline \multirow{2}{*}{ France } & 0.64 & 0.71 & 0.03 & -0.19 & 0.54 & 2580 \\
\hline & $(0.28)$ & $(0.19)$ & $(0.19)$ & $(0.59)$ & $(0.20)$ & \\
\hline \multirow[t]{2}{*}{ Greece } & 1.94 & 0.46 & -1.13 & 0.97 & -0.32 & 2323 \\
\hline & $(0.91)$ & $(0.76)$ & $(0.58)$ & $(0.40)$ & $(2.31)$ & . \\
\hline \multirow[t]{2}{*}{ Ireland } & 0.76 & -1.27 & 0.41 & 1.03 & -0.39 & 2448 \\
\hline & $(0.87)$ & $(0.33)$ & $(0.37)$ & $(0.47)$ & $(0.38)$ & \\
\hline \multirow[t]{2}{*}{ Italy } & 0.97 & 0.41 & 0.26 & -0.03 & 0.57 & 2496 \\
\hline & $(0.39)$ & $(0.27)$ & $(0.27)$ & $(0.41)$ & $(0.32)$ & \\
\hline \multirow[t]{2}{*}{ Luxembourg } & 0.92 & -0.75 & 0.09 & -1.26 & -0.18 & 2496 \\
\hline & $(0.35)$ & $(0.37)$ & $(0.47)$ & $(1.26)$ & $(0.42)$ & \\
\hline \multirow[t]{2}{*}{ The Netherlands } & 0.73 & 0.58 & -0.20 & -1.35 & 0.17 & 2506 \\
\hline & $(0.33)$ & $(0.38)$ & $(0.42)$ & $(0.72)$ & $(0.57)$ & \\
\hline \multirow[t]{2}{*}{ Portugal } & -0.12 & 0.46 & -0.08 & 0.15 & 1.32 & 2436 \\
\hline & $(0.56)$ & $(0.36)$ & $(0.45)$ & $(0.58)$ & $(0.36)$ & \\
\hline
\end{tabular}

Notes: Newey-West standard errors (in parentheses) allow for item-specific autocorrelation up to 12 months. Sample: JAN 97-DEC 02. 


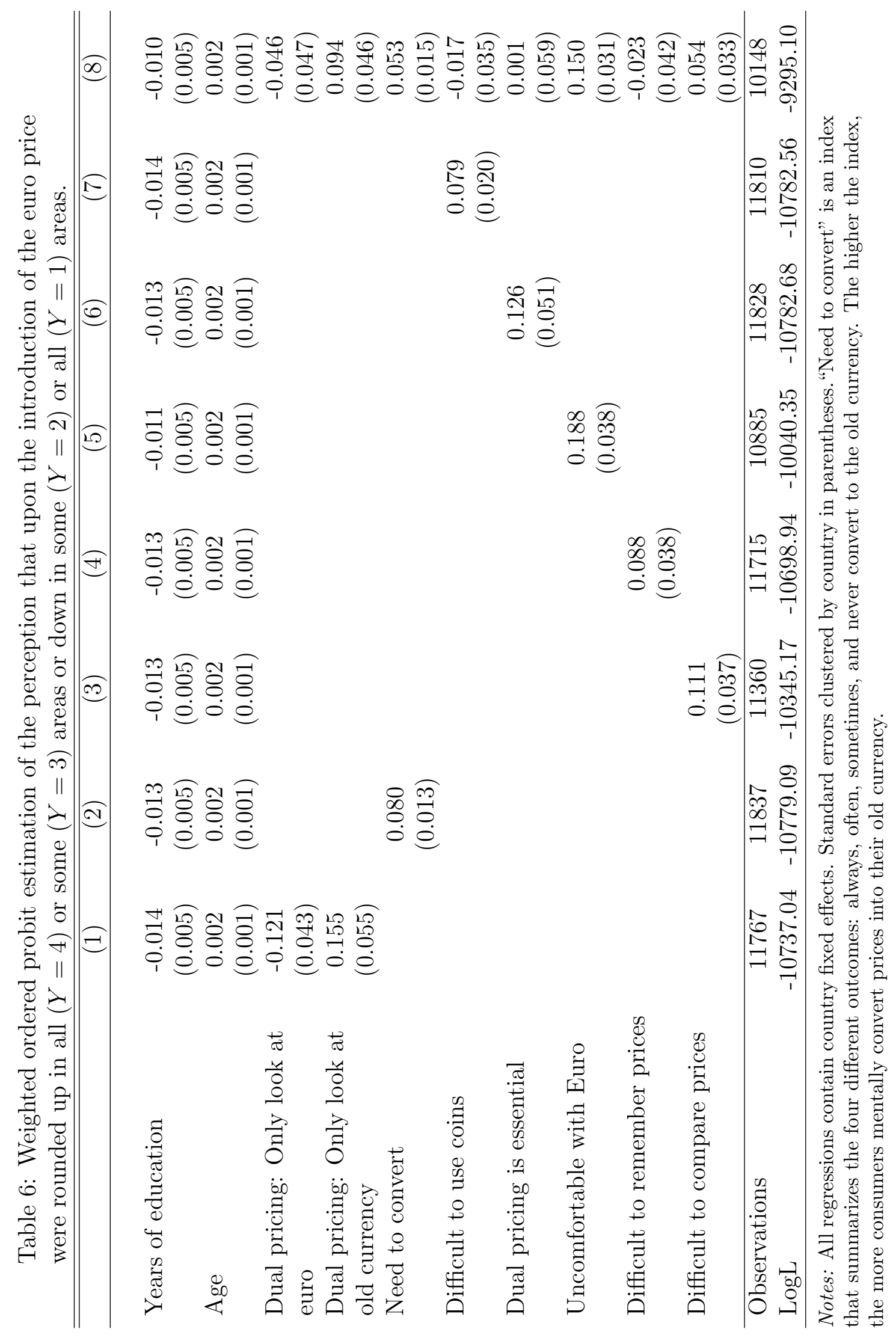




\section{A Main data sources}

Eurostat's HICP: The consumer price index is a measure of the general relative change of the prices of goods and services used by households for private consumption. In order to measure just the price change, weights are fixed over time (Laspeyres-type index, EUROSTAT (December 2001) ). These data contain information on 93 different aggregated items. We use the monthly price indices from January 1997 to December 2002.

Economist Intelligence Unit: The EIU collects, on a yearly basis, the prices of several goods in several cities from around the world. The EIU researchers collect information about prices twice a year EIU. Survey prices are gathered and listed from three types of stores: supermarkets, medium-priced retailers, and more expensive specialty shops. Only outlets, where items of internationally comparable quality are available for normal sale, are visited. The statistical design is weak, but the purpose of these data is just to classify products based on their approximate price level. The information from the EIU is then used by averaging over items and cities every time prices for multiple items and/or cities match one item from the Eurostat data. This procedure attenuates possible measurement errors. As a specification check, the models have been estimated using price averages over the entire time period available, and results were very similar.

The match: The time frequency and the items covered do not perfectly match. We manage to combine 46 items from the Eurostat data (50 percent) with prices in levels from the EIU data. Table 4 shows these items with the corresponding average price. 


\begin{tabular}{lcccc} 
Data & Eurostat & EIU & Consumer Survey & Eurobarometer \\
\hline \hline Type & panel & panel & panel & cross-sec. \\
Frequency & monthly & yearly & monthly & - \\
Time spanned & $1 / 97-12 / 02$ & $90-03$ & $1 / 85-11 / 03$ & $4 / 2002$ \\
Countries & 17 & 15 & 17 & 12 \\
\# of items & $\underbrace{94}_{4}$ & 303 & - & - \\
\# items matched & & & - & -
\end{tabular}

Eurobarometer: This survey is based on approximately 1000 interviews per member state. The 2002 survey mostly covers issues related to the introduction of the euro. Information extracted from this source always uses the appropriate sample weights.

Retailer concentration: The data has been taken from an internal working paper of the European Commission's Internal Market DG European Commission (2000). 